\title{
Perancangan Sistem Informasi Peminjaman Buku Diperpustakaan Menggunakan Bahasa Pemrograman PHP Dan Database Mysql
}

\author{
Regina Adelia ${ }^{1}$, Surmayanti ${ }^{2}$ \\ ${ }^{1}$ Universitas Putra Indonesia "YPTK" Padang, Indonesia \\ ${ }^{2}$ Universitas Putra Indonesia "YPTK" Padang, Indonesia \\ Email: reginaadelia246@gmail.com, surmayanti1994@gmail.com
}

\begin{abstract}
Web design of borrowing books at SMAN 1 Lembah Melintang Pasaman Barat Library aims to make it easier for librarians to enter books that were previously done manually, thus saving time. In this application I make it easy for library staff to do computerized input so that it can be efficient and effective. Application of SMAN 1 Valley Melintang Valley Pasaman Barat Library. The library makes it easy for library staff to enter new book data, member data and employee data at SMAN 1 Lembah Valley Pasaman Barat Library. Book data that has been inputted is stored with a MySQL database so that the data is safe.This research helps in establishing a book loan system. The design system in making a book loan application at SMAN 1 Lembah Melintang Pasaman Barat was developed by using some software namely Xampp, Sublime Text, Server which is a combination of Web Server, PHP and MySQL.
\end{abstract}

Keywords web design, library,book data, input, web server, and mysql.

\begin{abstract}
Abstrak
Desain web buku pinjam di Perpustakaan SMAN 1 Lembah Melintang Pasaman Barat bertujuan untuk mempermudah pustakawan untuk memasukkan buku yang sebelumnya dilakukan secara manual, sehingga menghemat waktu. Dalam aplikasi ini saya membuatnya mudah bagi staf perpustakaan untuk melakukan input yang terkomputerisasi sehingga dapat efisien dan efektif. Aplikasi Perpustakaan SMAN 1 Lembah Melintang Lembah Pasaman Barat. Perpustakaan memudahkan staf perpustakaan untuk memasukkan data buku baru, data anggota dan data karyawan di Perpustakaan SMAN 1 Lembah Valley Pasaman Barat. Data buku yang telah diinput disimpan dengan database MySQL sehingga datanya aman. Penelitian ini membantu dalam membangun sistem pinjaman buku. Sistem perancangan dalam membuat aplikasi pinjaman buku di SMAN 1 Lembah Melintang Pasaman Barat dikembangkan dengan menggunakan beberapa perangkat lunak yaitu Xampp, Sublime Text, Server yang merupakan gabungan dari Web Server, PHP dan MySQL.
\end{abstract}

Kata kunci: : perancangan web, pustaka, data buku, input, web server, php dan mysql.

\section{Pendahuluan}

Dalam era globalisasi saat ini teknologi informasi sangat membantu meringankan pekerjaan pada semua bidang kehidupan manusia. Salah satu diantaranya adalah bidang pendidikan. Karena kebutuhan dunia pendidikan demikian tinggi, tentulah harus dihadapi dengan kesiapan yang optimal sematamata demi kebutuhan anak didik. Salah satu unsur penting agar menjadi sekolah yang dapat mencetak anak didik yang baik adalah tersedianya perpustakaan sekolah yang lengkap serta didukung dengan administrasi data perpustakaan yang baik. Perpustakaan sekolah sangat erat hubungannya dengan pelaksanaan pembelajaran di sekolah. Pengelolaan administrasi perpustakaan secara umum sebenarnya telah dilakukan dengan baik oleh semua sekolah. Hanya kadar substansi pelaksanaanya sangat beragam antara sekolah yang satu dengan lainnya.

Pada sekolah-sekolah biasa daya dukung masyarakatnya masih tergolong rendah, pengelolaan administrasi perpustakaan pun masih sederhana. Sedangkan, pada sekolah-sekolah biasa yang daya dukung masyarakatnya besar, bahkan mungkin sangat besar, tentu saja pengelolaan administrasi perpustakaannya cenderung lebih maju. Untuk pengelolaan administrasi perpustakaan yang baik salah satunya dengan komputerisasi. Komputer dapat membantu dalam pengolahan data perpustakaan. Semua informasi yang dibutuhkan disimpan dalam sebuah database agar dapat digunakan sesuai dengan kebutuhan.

\section{Metode Penelitian}

Metode penelitian merupakan tahap penelitian yang dilakukan dalam menyelesaikan suatu masalah. Tahapan penelitian ini dilakukan dengan beberapa metode penelitian, antara lain : (1) Penelitian Lapangan (Field Research)

(a) Observasi (Pengamatan) Pada tahapan ini dilakukan pengamatan lapangan dengan cara melihat serta mempelajari permasalahan tentang sistem peminjaman buku perpustakaan di SMAN 1 Lembah Melintang Pasaman Barat.

Diterima Redaksi : 14-03-2020 | Selesai Revisi : 18-04-2020 | Diterbitkan Online : 30-04-2020 
(b) Wawancara (Interview) Untuk mendapatkan data dan informasi yang berhubungan dengan persediaan obat. dilakukan wawancara langsung dengan pihak perpustakaan, yaitu Ibuk Desi Yulfiana, S.Pd.I, wawancara dilakukan di SMAN 1 Lembah Melintang Jl. Kampung Juar, Ujuang Gadiang, Kec. Lembah Melintang, Kab. Pasaman Barat.

(2) Penelitian Pustaka (Library Research) ialah Penelitian dilakukan untuk mencari, mengumpulkan dan mempelajari data dari buku-buku, internet, serta literatur-literatur yang berhubungan dengan permasalahan yang dijadikan sebagai objek penelitian. (3)Penelitian Laboratorium (Laboratory Research) penelitian laboratorium merupakan tahap penelitian yang dilakukan dengan cara research menggunakan komputer guna untuk mempraktekkan langsung hasil dari analisa dan mencoba program yang bertujuan untuk menguji keakuratan sistem yang akan digunakan. Penelitian laboratorium ini berkaitan dengan hardware dan software yang digunakan dalam penelitian.

\section{Hasil dan Pembahasan}

Sebelum merancang sebuah sistem informasi baru pada sebuah perusahaan perlu adanya gambaran mengenai sistem yang sedang berjalan untuk dilakukan analisa terhadap sistem tersebut. Analisa yang dilakukan terhadap sistem harus bisa mengidentifikasi masalah yang sedang dihadapi perusahaan, memahami penyebab terjadinya masalah tersebut serta mampu memberikan penyelesaian masalah berupa solusi yang dapat memperbaiki kelemahan pada sistem yang sedang berjalan.

Analisa sistem yang dilakukan bertujuan untuk mengetahui kelemahan-kelemahan yang terjadi pada sistem lama. Karena dengan dilakukannya analisa sistem yang sedang berjalan akan dapat memberikan kemudahan di dalam perancangan dan pembangunan terhadap sistem yang akan dibangun atau sistem baru. Dengan dilakukannya analisa terhadap sistem lama nantinya akan dapat dijadikan sebagai perbandingan, pengkoreksian serta pengembangan dan perancangan kearah sistem yang baru.

Pembahasan adalah penjelasan dasar, hubungan dan generalisasi yang ditunjukkan oleh hasil. Uraiannya menjawab pertanyaan penelitian. Jika ada hasil yang meragukan maka tampilkan secara objektif.

\subsection{Aliran Sistem Kerja Lama}

Sistem perpustakaan pada perpustakaan SMAN 1 Lembah Melintang Pasaman Baratcara penggunjung datang perpustakaan untuk melakukkan peminjaman buku dan mencari buku yang ingin dipinjam di rak buku yang telah tersedia.

Berikut ini proses peminjaman buku yang sedang berjalan di perpustakaan SMAN 1 Lembah Melintang Pasaman Barat. (1) Siswa datang langsung ke perpustakaan, untuk melakukkan pencarian buku yang ingin dipinjamnya, (2)Kemudian setelah siswa mendapatkan buku yang ingin dipinjamnya, siswa dapat membaca buku secara langsung di perpustakaan atau jika siswa ingin melakukkan peminjaman buku, siswa harus terlebih dahulu mengunjungi petugas perpustakaan untuk melakukkan melakukkan peminjaman buku, (3) Setelah siswa melakukkan peminjaman buku pada pihak perpustakaan, kemudian pihak perpustakaan mencatat data peminjaman buku, (4) Kemudian setelah petugas perpustakaan melakukkan pencatatan transaksi peminjaman buku, pihak perpustakaan memberikan bukti peminjaman buku kepada siswa, (5) Apabila siswa ingin melakukkan pengembalian buku, siswa harus mengunjungi petugas perpustakaan kembali, dan menyerahkan buku yang dipinjam berserta bukti perminjaman buku, (6) Peminjaman buku dapat dilakukkan selama 6 bulan, atau satu semester, jika siswa tidak mengembalikkan buku sesuai dengan waktu yang telah ditetapkan, maka siswa tidak akan menerima surat keterangan bebas pustaka dari pihak perpustakan, (7) Surat keterangan bebas pustaka ini sebagai syarat untuk siswa yang ingin melakukkan penerimaan lapor, jika siswa tidak mendapatkan surat keterang bebas pustaka, maka siswa tidak akan diberikan lapor semester oleh wali kelas, dan wali kelas menganjurkan agar siswa tersebut mengurus surat keterangan bebas pustaka, sebelum selesai penerimaan lapor. 


\subsection{Use Case Diagram}

Use case bekerja dengan cara mendeskripsikan tipikal interaksi antara user sebuah sistem dengan sistemnya sendiri melalui sebuah cerita bagaimana sebuah sistem dipakai seperti pada gambar 1 .

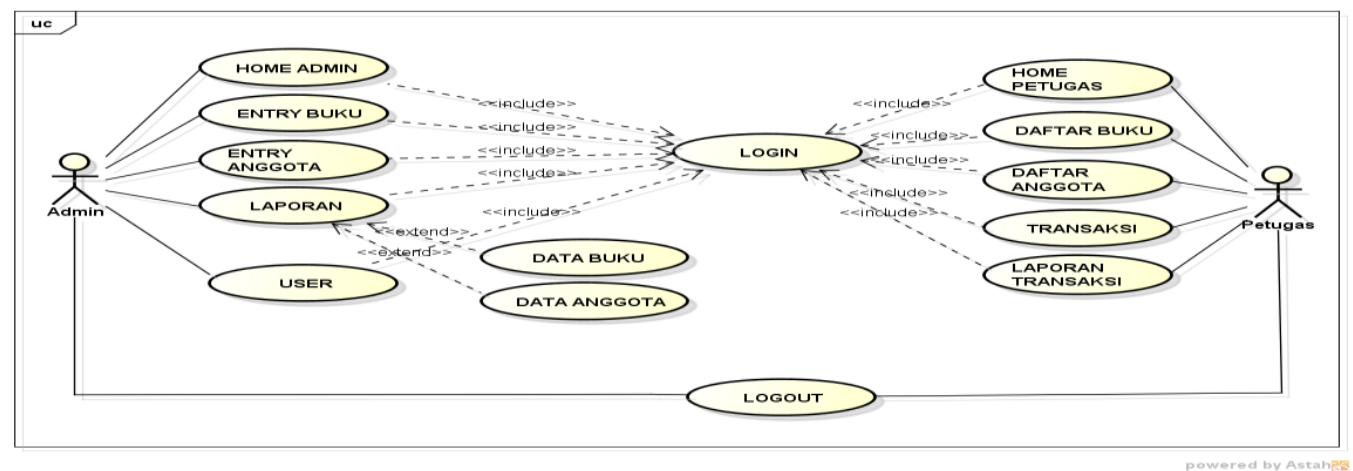

Gambar 1. Use Case Diagram Perpustakaan

\subsection{Class Diagram}

Class diagram mendeskripsikan jenis-jenis objek system dari berbagai macam hubungan statis yang terdapat diantara mereke. Class diagram juga menunjukkan property sebuah class dan batasan-batasan yang terdapat dalam hubungan objek-objek tersebut. Class diagram pada sistem informasi penjualan dapat dilihat pada gambar 2 .

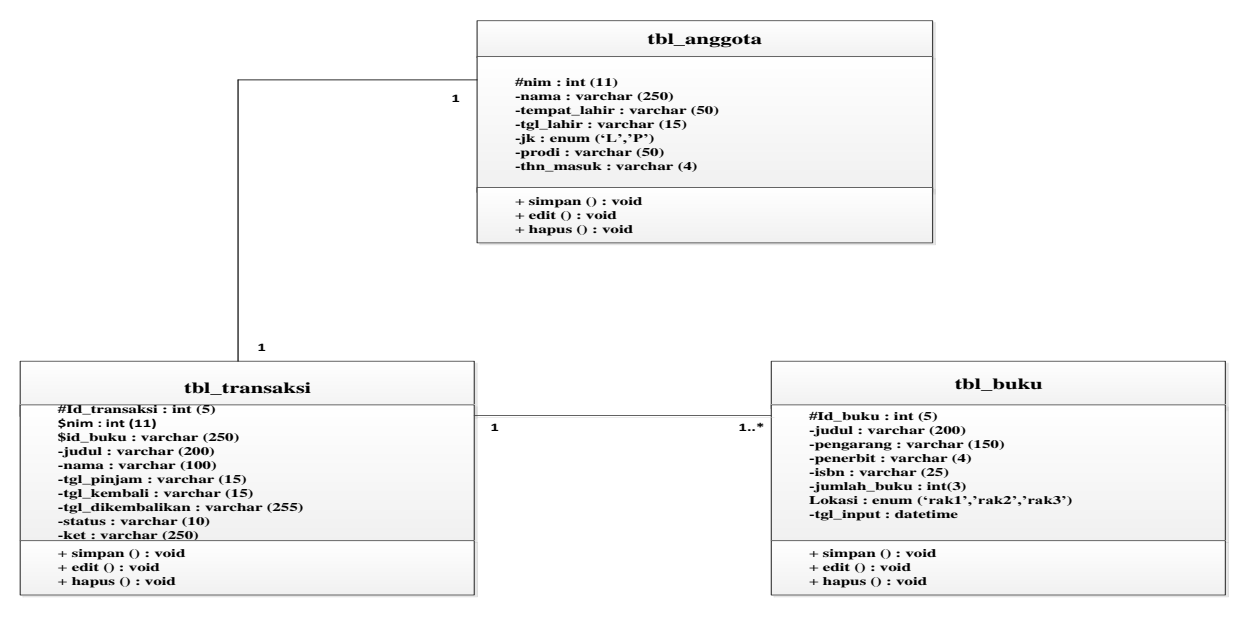

Gambar 2 Class Diagram

\subsection{Sequence Diagram}

Sequence Diagram digunakan untuk menggambarkan skenario atau rangkaian langkah-langkah yang dilakukan sebagai respon dari sebuah event untuk menghasilkan output tertentu. Diawali dari apa yang men-trigger aktifitas tersebut, proses dan perubahan apa saja yang terjadi secara internal dan output apa yang dihasilkan.

\section{Sequence Diagram Admin}

Sequence diagram admin merupakan interaksi admin terhadap sistem yang digambarkan seperti pada gambar 3: 
Regina Adelia, Surmayanti

Jurnal Teknologi Vol 10 No 1 (2020 ) 14-21

1. Sequence Diagram Admin Menu Utama

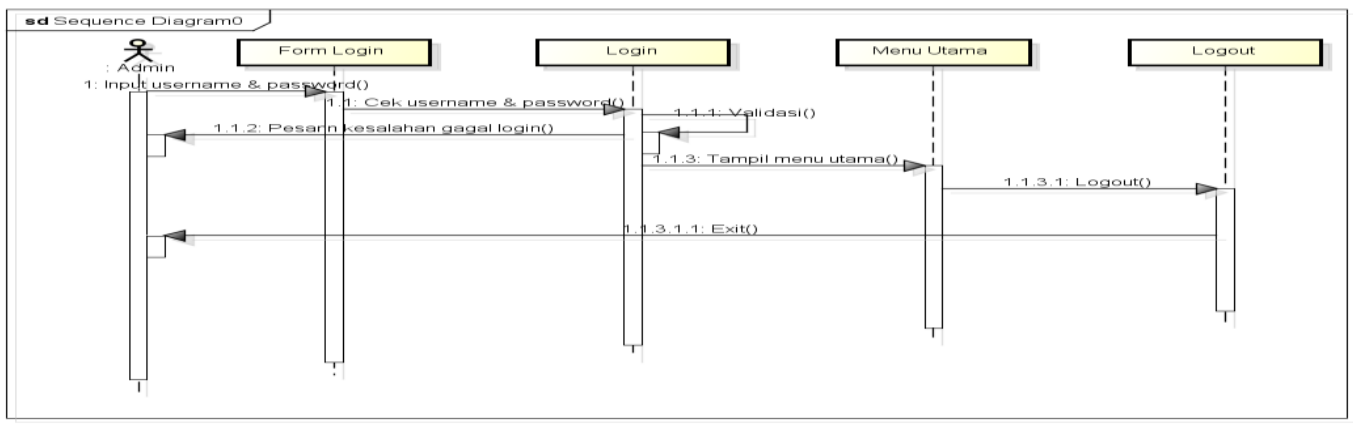

Gambar 3 Sequence Diagram Admin Menu Utama

2. Sequence Diagram Admin Entry Buku

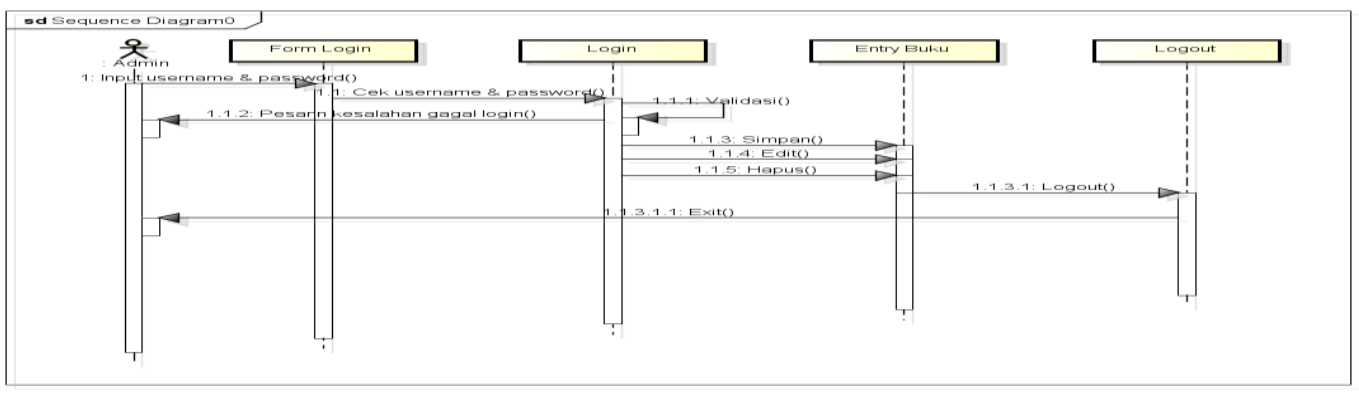

Gambar 4 Sequence Diagram Admin Entry Buku

3. Sequence Diagram Admin Entry Data Anggota

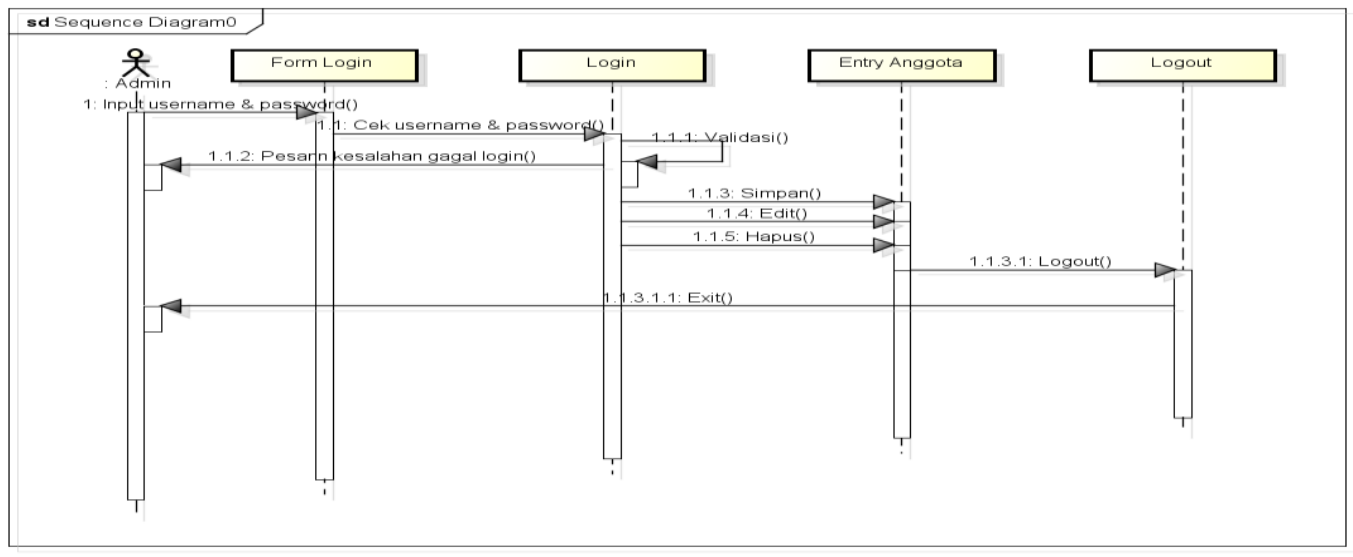

Gambar 5 Sequence Diagram Admin Entry Data Anggota

4. Sequence Diagram Admin Lihat Laporan Data Buku 
Regina Adelia, Surmayanti

Jurnal Teknologi Vol 10 No 1 (2020 ) 14-21

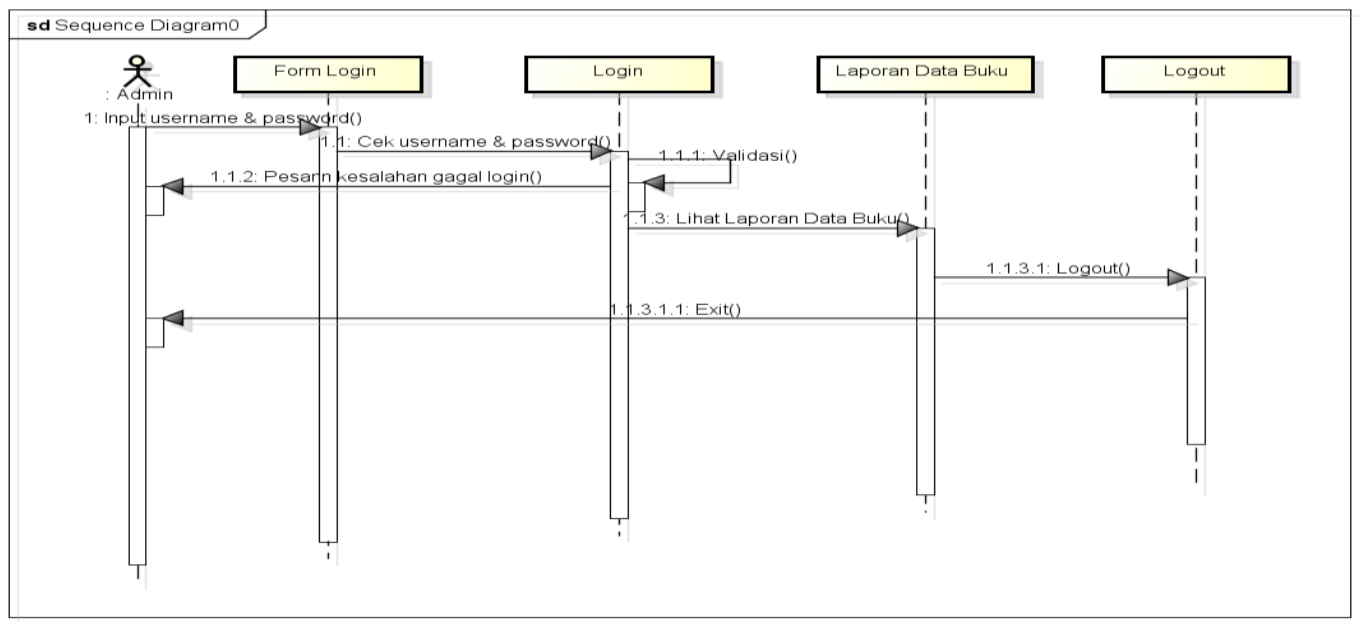

powered by Astahel

Gambar 6 Sequence Diagram Admin Lihat Laporan Data Buku

5. Sequence Diagram Admin Lihat Laporan Data Anggota

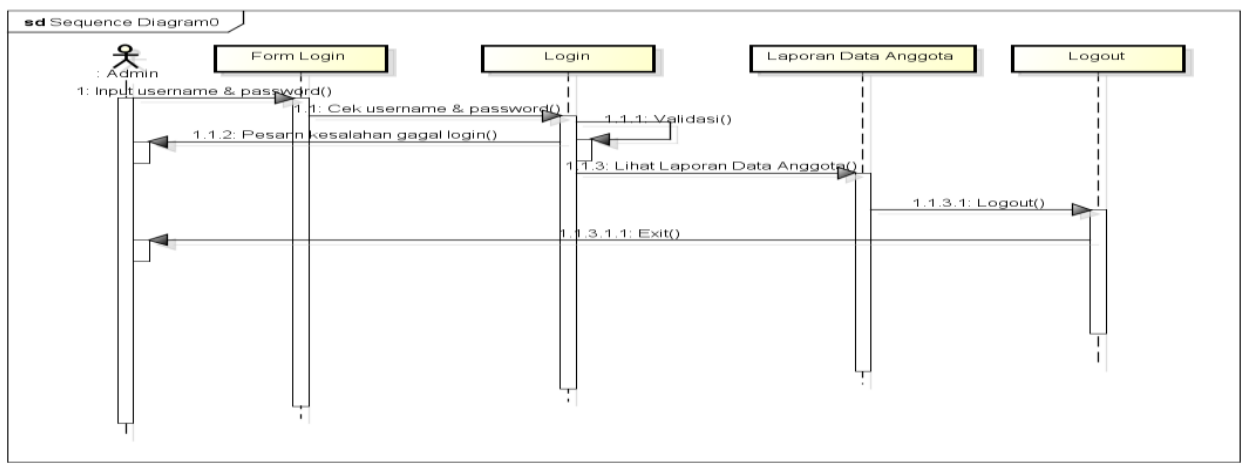

Gambar 7 Sequence Diagram Admin Lihat Laporan Data Anggota

6. Sequence Daigram Petugas Kelola Transaksi

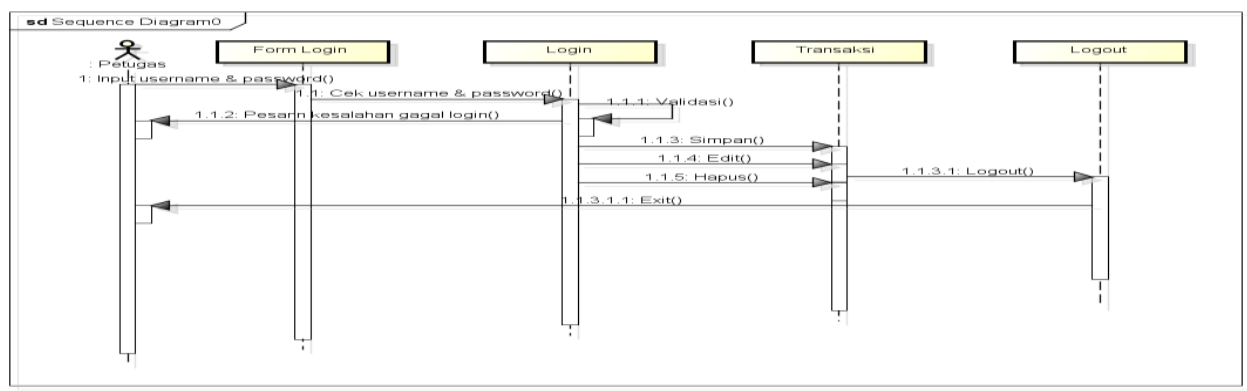

Gambar 8 Sequence Diagram Petugas Kelola Transaksi 
7. Sequence Diagram Petugas Lihat Laporan Transaksi

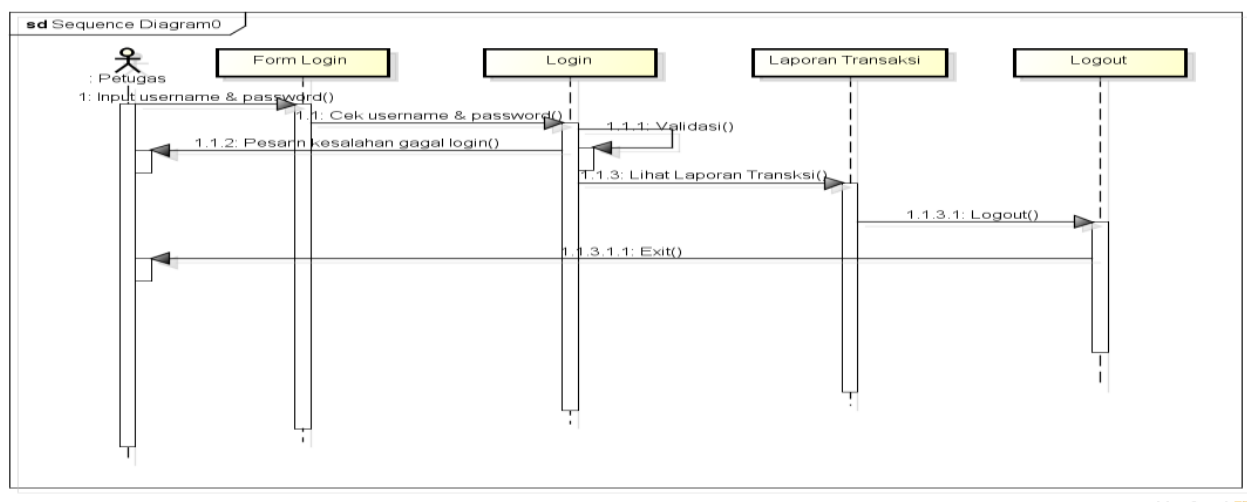

Gambar 9 Sequence Diagram Petugas Lihat Laporan Transaksi

\subsection{Activity Diagram Admin}

Activity Diagram Admin menggambarkan segala aktivitas yang bisa dilakukan admin terhadap sistem yang dimulai dengan melakukan login terlebih dahulu barulah bisa memilih aktivitas yang akan dilakukan melalui menu-menu pilihan yang ada. Activity Diagram Admin dapat dilihat pada Gambar 10.

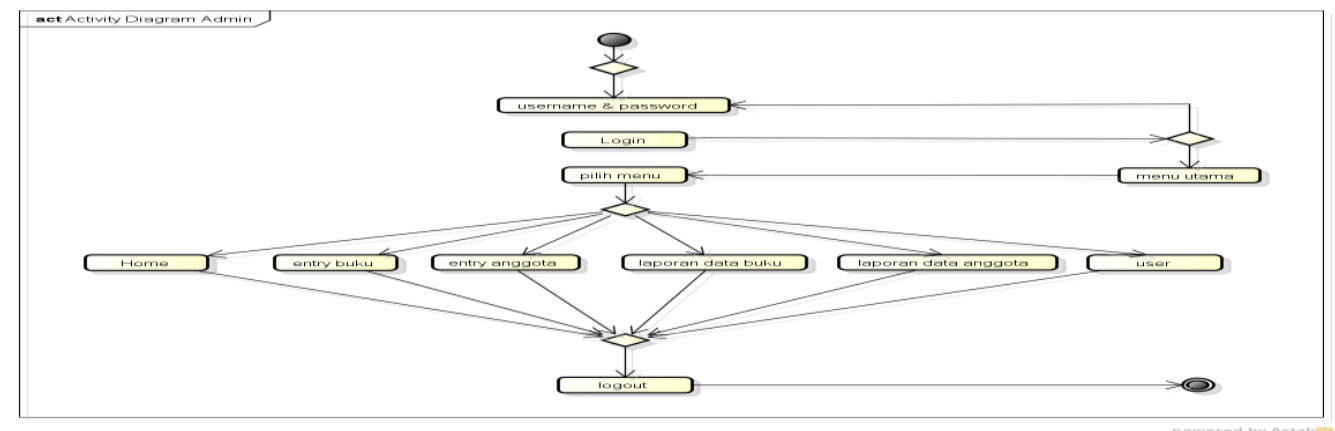

Gambar 10 Activity Diagram Admin

\subsection{Pengujian Sistem}

\section{Tampilan Home Perpustakaan}

Tampilan halaman utama menampilkan bentuk halaman utama sistem saat user mengakses halaman web. Setelah admin sukses melakukan login sistem akan mengalihkan ke halaman home yang berfungsi sebagai pusat kegiatan admin. Tampilan halaman home terdapat menu pada gambar 11.

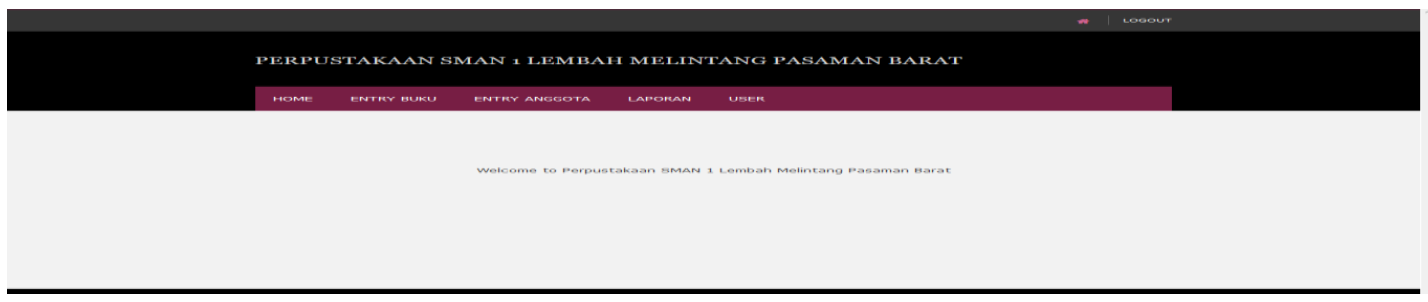

Gambar 11 Tampilan Home Perpustakaan 


\section{Tampilan Form Login}

Untuk mengakses Sistem Informasi Perpustakaan inin admin harus memasukkan id beserta password nya pada menu login, lalu menekan klik login pada form login. Gambar form login dapat dilihat pada gambar 12.

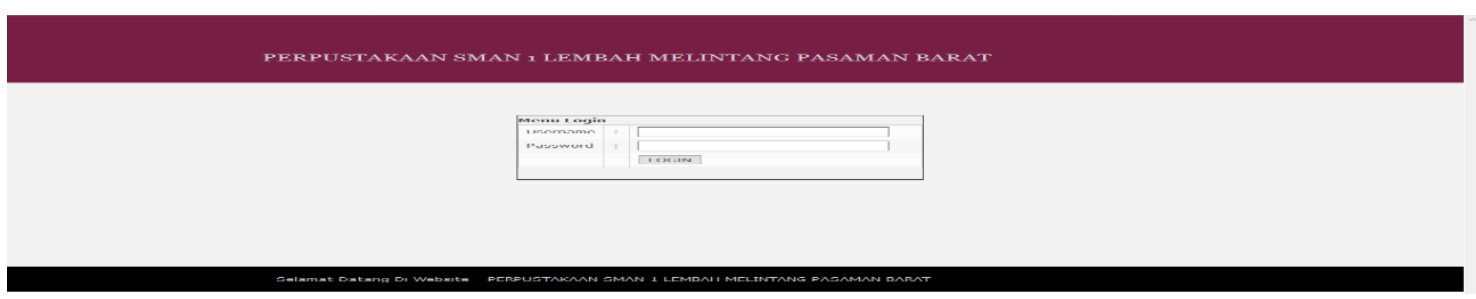

Gambar 12 Tampilan Form Login

\section{Tampilan Laporan Data Buku Pada Admin}

Pada tampilan data buku, admin memperlihatkan data-data buku perpustakaan yang telah terdaftar pada form laporan buku. Form ini berfungsi memasukkan data buku baru dan data buku lama.selengkap nya dapat dilihat pada Gambar 13.

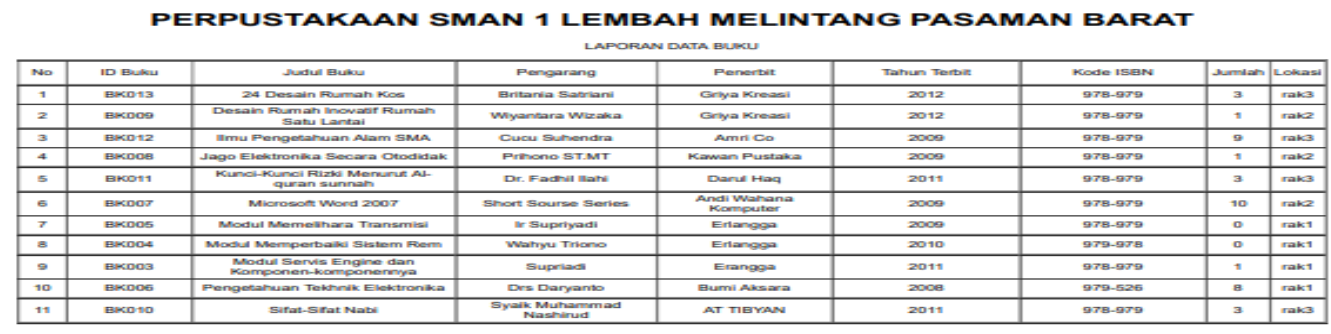

Petewgas Barat 06-01-2000

Gambar 3.21 Tampilan Laporan Data Buku Pada Admin

\section{Kesimpulan}

Dari penelitian yang penulis lakukan terhadap sistem peminjaman buku pada Perpustakaan SMAN 1 Lembah Melintang Pasaman Barat, serta menganalisa permasalahan yang ada maka dapat ditarik beberapa kesimpulan yaitu : (1) Dengan adanya penerapan aplikasi perpustakaan sekolah, dapat mempermudah petugas perpustakaan dalam proses penginputan data transaksi peminjaman buku, (2) Dengan adanya aplikasi perpustakaan sekolah mengunakan bahasa pemrograman PHP, membuat sistem perpustkaan sekolah yang lebih praktis dan mudah digunakan, (3) Dengan adanya suatu media penyimpanan data yang lebih terjamin dengan penerapan sistem yang baru ini, karena data-data tersimpan dalam bentuk file dengan adanya database, maka keamanan data dan keakuratan data lebih terjamin, (4) Dengan adanya aplikasi perpustakan yang terkomputerisasi, mengurangi penginputan data peminjaman buku dan penginputan data buku, yang dilakukan oleh petugas perpustakaan.

\section{Daftar Rujukan}

[1] Arif,Saiful Nur, Wanda, Ayu Putri., dan Masudi, Abdi. 2013. Aplikasi Administrasi Perpustakaan Berbasis WEB SMK Swasta Brigjend Katamso Medan. Jurnal SAINTIKOM Vol.12, No. 1.25-36.

[2] Asmara, Rini.2016."Sistem Informasi Pengolahan Data Penanggulangan Bencana Pada Kantor Badan Penanggulangan Bencana Daerah(BPBD) Kabupaten Padang Pariaman". Jurnal J-Click Vol 3 No 2. 80-91.

[3] Fatmawati, Endang.2015." Technology Acceptance Model (TAM) Untuk Menganalisis Penerimaan Terhadap Sistem Informasi Perpustakaan". Jurnal Iqra', Vol 09,No 01.1-13.

[4] Handayani, Sri. 2016. Sistim Informasi E-commerce untuk Jaringan Penjualan Sepeda Motor Bekas Kabupaten Kampar(Studi Kasus:Adira Finance). Jurnal Rekayasa Dan Manajemen Sistem Informasi , Vol.2, No 2. 106-111.

[5] Mardison. 2015."Perancangan Dan Implementasi E-commerce Pada Rumah Songket Pusako Minang Pandai Sikek". Jurnal KomTekInfo Fakultas Ilmu Komputer, Vol.2, No.2. 9-13.

[6] Prabowo, Faizal Ari, dan Syani, Mamay. 2016. "Sistem Informasi Pengolahan Sertifikat Berbasis Web Di Divisi Training Seamolec". Jurnal Masyarakat Informatika Indonesia, Vol 2,No 1. 73-81.

[7] Prasetyo,Andri dan Susanti, Rahel. 2016."Sistem Informasi Penjualan Berbasis Web Pada PT. Cahaya Sejahtera Sentosa Blitar". JITIKA,Vol 10 , No 2. 1-16. 
[8] Rubiati, Nur.2018.Aplikasi Informasi Pelayanan Fitness Pada Golden Fitness Center Dumai Dengan Bahasa Pemrograman PHP. Jurnal Informatika, Manajemen dan Komputer, Vol 10,No. 1. 1-6

[9] Gusman, A. P. (2019). ANALISA PERANCANGAN DAN IMPLEMENT ASI PEMESANAN SECARA ONLINE BERBASIS COSTUMER RELATIONSHIP MANAGEMENT (CRM). MAJALAH ILMIAH, 26(1), 7-13.

\section{PETUNJUK PENULISAN REFERENSI}

1. Referensi yang berasal dari buku Aturan penulisan: Author, Initials/First name., Year. Title of book. Edition. Place of publication: Publisher. Contoh:

Redman, P., 2006. Good essay writing: a social sciences guide. 3rd ed. London: Open University in assoc. with Sage.

2. Referensi yang berasal dari jurnal

Aturan penulisan: Author, Initials., Year. Title of article. Full Title of Journal, Volume number (Issue/Part number), Page numbers.

Contoh:

Boughton, J.M., 2002. The Bretton Woods proposal: an in depth look. Political Science Quarterly, 42 (6), pp.56478.

3. Referensi yang berasal dari laporan seminar

Aturan penulisan: Authorship author, editor or organisation, Year. Full title of conference report. Location, Date, Publisher: Place of publication.

Contoh:

UNDESA (United Nations Department of Economic and Social Affairs), 2005. 6th Global forum on reinventing government: towards participatory and transparent governance. Seoul, Republic of Korea 24-27 May 2005. United Nations: New York.

4. Referensi yang berasal dari makalah seminar/prosiding

Aturan penulisan: Authorship, Year. Full title of conference paper. In: followed by Editor or name of organisation, Full title of conference. Location, Date, Publisher: Place of publication.

Contoh:

Brown, J., 2005. Evaluating surveys of transparent governance. In: UNDESA (United Nations Department of Economic and Social Affairs), 6th Global forum on reinventing government: towards participatory and transparent governance. Seoul, Republic of Korea 24-27 May 2005. United Nations: New York.

5. Referensi yang berasal dari desertasi

Aturan penulisan: Author, Year of publication. Title of dissertation. Level. Place of University (If not clear from the name of the University): Name of University.

Contoh:

Richmond, J., 2005. Customer expectations in the world of electronic banking: a case study of the Bank of Britain. Ph. D. Chelmsford: Anglia Ruskin University.

6. Referensi yang berasal dari situs web

Aturan penulisan: Authorship or Source, Year. Title of web document or web page. [Medium] (date of update) Available at: include web site address/URL(Uniform Resource Locator) and additional details such as access or routing from the home page of the source. [Accessed date].

Contoh:

National electronic Library for Health, 2003. Can walking make you slimmer and healthier? (Hitting the headlines article) [Online] (Updated 16 Jan 2005)

Tersedia di : http://www.nhs.uk.hth.walking. [Accessed 10 April 2005] 